\title{
Investigating the utility of COVID-19 antibody testing in end-stage renal disease patients receiving haemodialysis: a cohort study in the United Kingdom
}

Olivia Wickens ${ }^{1}$, Rajkumar Chinnadurai ${ }^{1,2^{*}}$ D, Fahmida Mannan ${ }^{1}$, Frida Svendsen ${ }^{1}$, Mirza Yasar Baig ${ }^{1}$, Chukwuma Chukwu ${ }^{1,2}$, Ibrahim Ali ${ }^{1,2}$, Christina Summersgill', Dawn Evans' ${ }^{1}$, Berckley V. Antoine ${ }^{1}$, Julie Oxton ${ }^{3}$, Nathan Mairs ${ }^{3}$, Emma Flanagan $^{1}$, Robert Oliver ${ }^{3}$, Philip A. Kalra ${ }^{1,2}$ and Dimitrios Poulikakos ${ }^{1,2}$

\begin{abstract}
Background: End-stage renal disease (ESRD) patients receiving haemodialysis (HD) are a vulnerable group of patients with increased mortality from COVID-19. Despite improved understanding, the duration of host immunity following COVID-19 infection and role of serological testing alone or in addition to real-time reverse transcription polymerase chain reaction (rRT-PCR) testing in the HD population is not fully understood, which this study aimed to investigate.

Methods: There were two parts to this study. Between 15th March 2020 to 15th July 2020, patients receiving HD who tested positive on rRT-PCR for SARS-CoV-2 were recruited into the COVID-19 arm, whilst asymptomatic patients without a previous diagnosis of COVID-19 were recruited to the epidemiological arm of the Salford Kidney Study (SKS). All patients underwent monthly testing for anti-SARS-CoV-2 antibodies as per routine clinical practice since August 2020. The aims were twofold: firstly, to determine seroprevalence and COVID-19 exposure in the epidemiological arm; secondly, to assess duration of the antibody response in the COVID-19 arm. Baseline characteristics were reviewed between groups. Statistical analysis was performed using SPSS. Mann-Whitney U and Chi-squared tests were used for testing significance of difference between groups.

Results: In our total HD population of 411 patients, 32 were PCR-positive for COVID-19. Of the remaining patients, 237 were recruited into the SKS study, of whom 12 (5.1\%) had detectable anti-SARS-CoV-2 antibodies. Of the 32 PCR-positive patients, 27 (84.4\%) were symptomatic and 25 patients admitted to hospital due to their symptoms. Of the 22 patients in COVID-19 arm that underwent testing for anti-SARS-CoV-2 IgG antibodies beyond 7 months, all had detectable antibodies.

A higher proportion of the patients with COVID-19 were frail compared to patients without a diagnosis of COVID(Continued on next page)
\end{abstract}

\footnotetext{
* Correspondence: rajkumar.chinnadurai@srft.nhs.uk

'Department of Renal Medicine, Salford Royal NHS Foundation Trust, Salford M6 8HD, UK

${ }^{2}$ Faculty of Biology, Medicine and Health, University of Manchester, Manchester, UK

Full list of author information is available at the end of the article
}

C C The Author(s). 2021 Open Access This article is licensed under a Creative Commons Attribution 4.0 International License, which permits use, sharing, adaptation, distribution and reproduction in any medium or format, as long as you give appropriate credit to the original author(s) and the source, provide a link to the Creative Commons licence, and indicate if changes were made. The images or other third party material in this article are included in the article's Creative Commons licence, unless indicated otherwise in a credit line to the material. If material is not included in the article's Creative Commons licence and your intended use is not permitted by statutory regulation or exceeds the permitted use, you will need to obtain permission directly from the copyright holder. To view a copy of this licence, visit http://creativecommons.org/licenses/by/4.0/ The Creative Commons Public Domain Dedication waiver (http://creativecommons.org/publicdomain/zero/1.0/) applies to the data made available in this article, unless otherwise stated in a credit line to the data. 


\begin{abstract}
(Continued from previous page)
$19(64.3 \%$ vs $34.1 \%, p=0.003)$. Other characteristics were similar between the groups. Over a median follow up of 7 months, a higher number of deaths were recorded in patients with a diagnosis of COVID-19 compared to those without ( $18.7 \%$ vs $5.9 \%, p=0.003)$.

Conclusions: Serological testing in the HD population is a valuable tool to determine seroprevalence, monitor exposure, and guide improvements for infection prevention and control (IPC) measures to help prevent local outbreaks. This study revealed HD patients mount a humoral response detectable until at least 7 months after COVID-19 infection and provides hope of similar protection with the vaccines recently approved.
\end{abstract}

Keywords: COVID-19, Antibody testing, Haemodialysis, End-stage renal disease

\section{Background}

Since the discovery of Coronavirus disease 2019 (COVID-19) in December 2019, caused by severe acute respiratory syndrome coronavirus- 2 virus (SARS-CoV2), we have witnessed a global pandemic. SARS-CoV-2 has become the seventh coronavirus to infect humans and the third identified coronavirus to cause a major outbreak in humans [1].

End-stage renal disease (ESRD) patients receiving haemodialysis (HD) have been identified as a particularly high-risk group of patients at increased risk of mortality from COVID-19 [2-4]. This is because many dialysis patients have underlying chronic co-morbidities, are often of an older age group and have an impaired immune response. In addition, maintenance HD patients have significantly increased risk of exposure to SARS-CoV-2 as they are unable to self-isolate, having to attend frequent HD sessions, usually thrice per week, with associated risks during transport.

Molecular testing via respiratory tract swabs, analysed by real-time reverse transcription polymerase chain reaction (rRT-PCR), remains the gold-standard diagnostic test for suspected COVID-19. However, false-negatives can occur with an insufficient sample quantity of viral genome, improper sampling or missing the window period of viral replication [5]. More recent tests involve viral antigen detection usually from nasopharyngeal (NP) swabs, which can provide results within $15 \mathrm{~min}$ [6]. Both viral nucleic acid and viral antigen tests only test for the presence of active infection and have no role in the identification of past infection, although they have been reported to continue to remain positive due to prolonged viral shedding for up to 63 days following the onset of symptoms [7, 8]. With high numbers of asymptomatic and pre-symptomatic cases or viral shedding post-infection, keeping infection transmission under control continues to remain an enormous challenge.

With the limitations of molecular testing for COVID19 , there has been much interest in the use of serological anti-SARS-CoV-2 antibody testing. With a broad spectrum of clinical presentation of COVID-19 from asymptomatic infection, or mild flu-like symptoms through to acute respiratory distress syndrome (ARDS), multi-organ failure and death, serological testing plays an important role in surveillance, epidemiological studies and as an indirect marker of infection. Serological testing can be used to monitor disease prevalence and evaluate screening measures and protocols aiming at limiting transmission within dialysis units. Additionally, serological testing is also essential to quantify the level and duration of antibody response after COVID-19 infection, as with loss of detectable anti-SARS-CoV-2 antibodies and shortlived humoral immunity there may be a risk of potential reinfection or viral reactivation, particularly whilst patients are awaiting vaccination [9]. This is of particular concern in the vulnerable category of ESRD patients receiving maintenance HD, which are a high-risk group of patients at increased morbidity and mortality from infection with SARS-CoV-2 due to their impaired immune responses to infection and vaccination [10].

To this end, this study aimed at determining the IgG seroprevalence among both asymptomatic patients without a diagnosis of COVID-19 and symptomatic or asymptomatic rRT-PCR positive patients in our HD population. Additionally, serological testing was used to assess the duration of antibody response and immunity in those infected with COVID-19. Baseline characteristics were compared between patients who tested positive and those who tested negative for SARS-CoV-2 by rRTPCR to determine if there were particular risk factors for infection.

\section{Methods}

Between 15th March 2020 to 15th July 2020, patients receiving HD who tested positive on rRT-PCR for SARSCoV-2 were recruited into the COVID-19 arm, whilst the remainder of patients were recruited to the epidemiological arm of Salford Kidney Study (SKS). SKS is a prospective observational study in the United Kingdom which has recruited chronic kidney disease patients since the year 2002. The ethical approval of SKS has been extended to include dialysis patients (both HD and peritoneal dialysis (PD)) since 2016. This research work has been performed in accordance with the Declaration of 
Helsinki and SKS has ethical approval obtained from the North West - Greater Manchester South Research Ethics Committee, UK (reference number: 15/NW/0818). All 269 patients involved in our observational analysis have signed an informed consent.

Details of patients recruited into SKS are elaborated in the Research Registry (https://www.researchregistry.com; researchregistry5962). In brief, this is longitudinal epidemiological study that involves annual blood sampling with samples processed and stored at $-75^{\circ} \mathrm{C}$ for subsequent research analysis (EDTA whole blood, serum, plasma, and citrate plasma). All adult patients who have provided informed consent are recruited to the SKS.

The protocol was amended to include a sub-study for COVID-19 positive patients in order to investigate the time course of development of antibodies and the longevity of antibody response in HD patients. This substudy included collection and storage of blood samples at recruitment (at or shortly after COVID-19 infection) and at intervals of 8 to 14 days on five occasions after infection, followed by six monthly interval samples. From August 2020 onwards, maintenance HD patients underwent COVID-19 IgG antibody testing at monthly intervals as per newly implemented routine clinical practice.

\section{Serological testing}

All sera collected was tested only for COVID-19 IgG antibody. The initial antibody tests were obtained on recruitment and the criterion for recruitment was being asymptomatic and not having a previous diagnosis of COVID-19. This initial research assay was measured via a CE marked chemiluminescent immunoassay (SNIBE, Shenzhen, China) and the analysis was performed by Medical Diagnostics Ltd. in conjunction with Affinity Biomarker Labs, with a result of $>1 \mathrm{AU} / \mathrm{ml}$ deemed positive [11]. The calculated clinical sensitivity and specificity according to manufacturer for the chemiluminescent analytical assay for SARS-CoV-2 IgG antibody was 91.21, and 97.3\%, respectively [11]. Subsequent antibody tests were performed via the Public Health England (PHE) approved Siemens' immunoassay using acridinium ester chemiluminescent technology [12], which became available in the hospital laboratory from 12th June 2020. From August 2020, monthly screening surveillance with COVID-19 IgG antibody testing with Siemens' immunoassay of the total HD cohort was implemented. An index $\geq 1.0$ was deemed positive for the Siemens' assay based on the manufacturer's assigned cut-off and sensitivity and specificity for the Siemens' assay were reported at 98.1 and $99.9 \%$ respectively [12].

\section{rRT-PCR testing}

Initial rRT-PCR testing was performed if a patient was suspected to have COVID-19 or was contact case of a person with confirmed COVID-19. A suspected case was defined as a person exhibiting symptoms and signs based on PHE criteria on screening prior to HD (or selfpresentation). A contact case was defined as a person who received HD during the same or subsequent shift (possible contact in waiting area) if there were greater than two positive cases in one shift. Suspected cases would be transferred directly to the main base dialysis unit (Salford Royal Hospital) for testing and assessment and for their next dialysis sessions. If the initial rRTPCR was negative for SARS-CoV-2 it was repeated at their following HD session, and if negative again and asymptomatic, they would return to their satellite unit. COVID-19 identification was performed via an upper respiratory tract swab for SARS-CoV2 by rRT-PCR. Screening with nasopharyngeal swabs by rRT-PCR for asymptomatic contact cases was performed in the satellite HD units. rRT-PCR remains the gold standard test for COVID-19, however its sensitivity depends on the patterns of viral shedding and the probability of a positive result varies over the course of infection. There is heterogeneity in reported accuracy from different studies with reported false negative rate ranging from $13 \%$ in symptomatic patients [13], to $30-40 \%$ in close contacts of confirmed cases against serological diagnosis with SARS-CoV-2 antibodies [14]. False-positive rates have been reported between 0.8 and $4.0 \%$ [15].

\section{Data collection}

Data was collected at study baseline (rRT-PCR date between March and July 2020) from the electronic patient records. This included demographics, body mass index (BMI), clinical frailty score (CFS) and comorbidities, including a history of diabetes and cardiovascular events. Blood results including full blood count, ferritin, and albumin were recorded at baseline or within 2 weeks from the monthly dialysis bloods for all available patients. All patients were followed up from study baseline to endpoints which included death, loss to follow up or an arbitrary study end date of 31st December 2020.

\section{Study definitions}

The comorbidity, medication and frailty data were collected at the time of the first antibody test date. A smoking history was defined as a patient reported history of smoking, irrespective of the number of cigarettes smoked. Cardiovascular disease (CVD) history included a composite of non-fatal cardiac arrest, acute coronary syndrome, myocardial infarction, peripheral vascular disease, cerebrovascular accident and congestive cardiac failure. Renin-angiotensin system inhibitors (RASi) medications included angiotensin converting enzyme inhibitors and angiotensin receptor 
blockers. Frailty status was determined using the CFS, with any patient with a score of five and above on the CFS was defined as being frail $[16,17]$.

\section{Statistics}

Statistical analysis was performed using SPSS version-23, licenced to the University of Manchester. Throughout the analysis, categorical values were expressed as number (\%), and the $p$-value was derived using the Chisquare test. As most of the continuous values were nonnormally distributed, they were expressed as median (interquartile range) and the Mann-Whitney $U$ test was used to calculate the $p$-value. Cox-regression analysis was used to study the strength of association between COVID-19 rRT-PCR positivity and all-cause mortality. To overcome the influence of competing risks, hazard ratios were derived by censoring at the competing event. (i.e., negative patients developing COVID-19 infection during follow-up). A p-value $<0.05$ was considered statistically significant in this study [18].

\section{Results}

Seroprevalence of COVID-19 in asymptomatic rRT-PCRnegative HD population

A total of 237 asymptomatic HD patients without a diagnosis of COVID-19 consented out of a total HD population of 411. All 237 patients were recruited to the epidemiological arm of SKS. In this group of patients blood samples obtained for the first antibody testing at recruitment were analysed via the chemiluminescent immunoassay performed at a median of 3 days (interquartile range (IQR) -2 to 14 ) from the rRT-PCR test. The seroprevalence of IgG to SARS-CoV-2 was $5.1 \%(n=12)$ in this group (Table 1). All 237 patients also had a negative rRT-PCR test between April and July 2020. The second antibody testing performed via the Siemens' antibody assay was at a median of 62 days (IQR 47-77) from the negative rRT-PCR test result. Of the $12 \mathrm{rRT}$ PCR negative patients who had detectable anti-SARSCoV-2 antibodies on the first antibody test, antibodies were detectable in $54.5-60 \%$ of patients at the monthly serological testing points during the follow-up period with the Siemens' assay (Fig. 1). Ten patients tested positive for COVID-19 on rRT-PCR testing during the follow-up period.
Serological testing in COVID-19 rRT-PCR-positive patients A total of 32 patients receiving HD who tested positive for SARS-CoV-2 by rRT-PCR were recruited into COVID-19 arm of the SKS. Twenty-seven patients (84.4\%) were symptomatic for COVID-19 and 25 patients (78.1\%) had a COVID-19 associated hospital admission. A COVID-19 associated hospital admission included patients who either tested positive on the date of hospital admission or during their admission. The first baseline antibodies were tested via the CE marked chemiluminescent immunoassay (SNIBE, Shenzhen, China) and the analysis was performed by Medical Diagnostics Ltd. in conjunction with Affinity Biomarker Labs. Of the 32 patients who had antibody testing at baseline, 31 (96.9\%) had detectable IgG to SARS-CoV-2. This was performed at a median of 22 days (IQR 16-36) from the positive rRT-PCR test result. Subsequent antibody testing from the second antibody testing point onward was performed via the Siemens' assay. Sera for COVID-19 antibodies were collected at regular time points, up to 6 times (median number of days prior to obtaining second, third, fourth, fifth and sixth samples were 120, 152, 185, 215 and 242 respectively), as seen in Table 2.

Of the 32 patients, one patient had undetectable antibodies from the second antibody test onwards. Another patient had undetectable antibodies from the second antibody until the sixth antibody test in which antibodies were then detected, which is the reason for the reduced percentage of patients with detectable antibodies at some of the sampling time points. In the sixth antibody collection point all the patients who underwent testing at this timepoint $(n=22)$ had detectable antibodies, with the one patient who had undetectable antibodies from the second test onwards not having testing at this period. There was also one patient who had undetectable antibodies on the first antibody test, who then was found to have positive antibodies on all subsequent testing.

After the first antibody testing, there was a decline in the number of COVID-19 rRT-PCR-positive patients who underwent serological testing during the follow-up period $(n=21 ; n=18 ; n=20, n=17, n=22$ at the second, third, fourth, fifth and sixth antibody samples respectively). The decline in patient numbers were due to death $(n=6)$, dialysis independence $(n=2)$ and not all samples were retrieved at the scheduled time points due to practical challenges related to the pandemic (transfer

Table 1 Antibody status and COVID-19 rRT-PCR positivity correlation at baseline (first antibody)

\begin{tabular}{llll}
\hline Variable & $\begin{array}{l}\text { Total } \\
\mathbf{2 6 9}\end{array}$ & COVID-19 PCR positive (32) & COVID-19 PCR negative (237) \\
\hline Number of patients with IgG antibody positive & $43(16 \%)$ & $31(96.9 \%)$ & $12(5.1 \%)$ \\
Time between Covid-19 PCR and 1st antibody level, days & $4(1-17)$ & $22(16-36)$ & $3(-2$ to 14) \\
\hline
\end{tabular}

Categorical variables are expressed as number (\%). Continuous variables are expressed as median (interquartile range) $r R T-P C R$ real-time reverse transcription polymerase chain reaction 


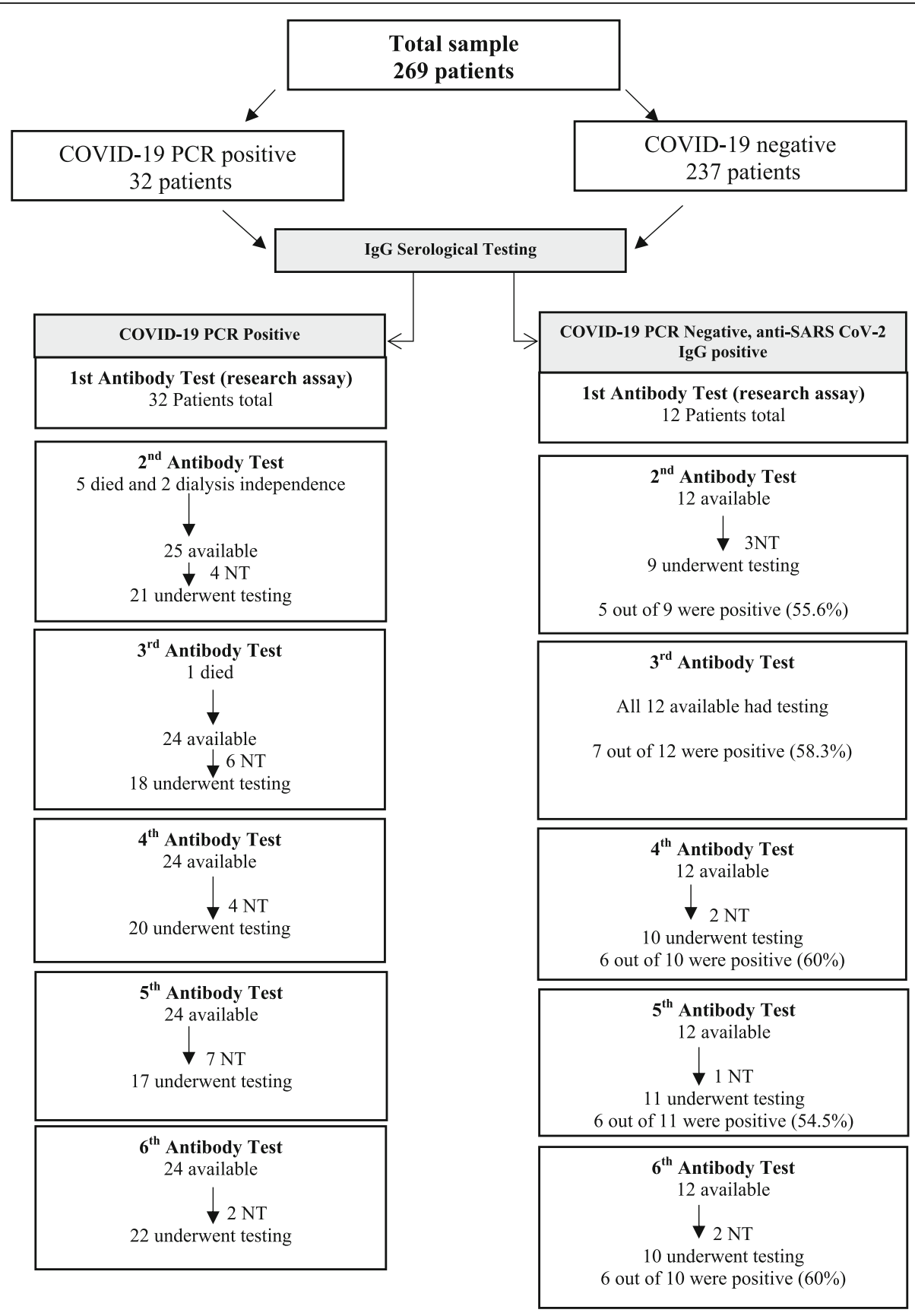

NT- not had test at this time point

Fig. 1 Representation of serological testing at various time points in SARS-CoV-2 seropositive patients

of patients between units and impact of the pandemic on research capacity), (Fig. 1).

Of the 22 rRT-PCR-positive patients that were revealed to have detectable antibodies at a median of 242 days (IQR 233-250) from PCR positivity, 17 were symptomatic with COVID-19, and 16 had a COVID-19 associated hospital admission. Although the number of patients with detectable IgG antibodies to SARS-CoV2 varied over the course of the study, seropositivity remained at least $88.2 \%$ or above at each sampling point. There were a total of 6 deaths during the follow-up period, of which 2 were secondary to COVID-19 infection. While not statistically significant, there was a trend towards a higher risk of all-cause mortality among patients who initially tested positive for COVID-19 via rRT-PCR at baseline after adjustment for possible 
Table 2 Trend of antibody status in the 32 positive patients

\begin{tabular}{|c|c|c|c|c|c|c|}
\hline Variable & First antibody & Second antibody & Third antibody & Fourth antibody & Fifth antibody & Sixth Antibody \\
\hline $\begin{array}{l}\text { Number of patients with } \lg G \text { antibody } \\
\text { level available }\end{array}$ & 32 & 21 & 18 & 20 & 17 & 22 \\
\hline $\begin{array}{l}\text { Number of patients with } \lg G \text { antibody } \\
\text { level positive }\end{array}$ & 31 (96.9\%) & 19 (90.5\%) & 17 (94.4\%) & 18 (90\%) & 15 (88.2\%) & $22(100 \%)$ \\
\hline $\begin{array}{l}\text { Median time between Covid-19 PCR } \\
\text { and antibody, days }\end{array}$ & $22(16-36)$ & $120(109-124)$ & $152(142-158)$ & 185 (174-189) & 215 (210-220) & $242(233-250)$ \\
\hline
\end{tabular}

Categorical variables are expressed as number (\%). Continuous variables are expressed as median (interquartile range). The first antibody testing was performed via a CE marked chemiluminescent immunoassay (SNIBE, Shenzhen, China) and the analysis was performed by Medical Diagnostics Ltd. in conjunction with Affinity Biomarker Labs. All subsequent antibody testing was performed by Siemens' immunoassay using acridinium ester chemiluminescent technology which was a Public Health England approved hospital assay)

confounders (HR 2.29, 95\% CI: 0.72-7.35). Therefore, COVID-19 infection was not an independent risk factor associated with all-cause mortality during the study period of interest (Supplementary Table 1).

\section{Comparison of baseline characteristics of COVID-19 rRT- PCR-negative and rRT-PCR-positive patients}

Baseline characteristics for the study population are presented as a comparison between these two groups in Table 3. The median age of the study population was 61 years (IQR 50-73) and a predominance of males and Caucasian ethnicity, though not significantly different between the groups. The groups were similar in the baseline clinical characteristics, including smoking history, body mass index (BMI), history of diabetes and cardiovascular diseases, apart from the proportion of patients in the COVID-19 positive group were more clinically frail $(64.3 \%$ vs $34.1 \%$; $p=0.003)$. Over a median follow up of 7.6 months, a higher proportion of deaths was observed in the COVID-19 positive group (18.7\% vs 5.9\%; $p<0.003)$, although 10 patients in the rRT-PCR negative group tested positive for COVID-19 on rRTPCR in the follow-up period, of which three required hospital admission.

\section{Discussion}

Our study has revealed a seroprevalence of $5.1 \%$ in the maintenance, asymptomatic HD population. In the 22 of the 32 COVID-19 rRT-PCR-positive patients who had antibodies tested beyond 7 months, $100 \%$ still had detectable anti-SARS-CoV-2 antibodies. The majority of baseline characteristics were similar between both COVID-19 rRT-PCR negative and positive patients, although there was a statistically higher prevalence of frailty in the rRT-PCR positive group.

Patients with ESRD receiving $\mathrm{HD}$, in particular incentre dialysis patients, have a higher chance of acquiring COVID-19 infection due to their regular contacts with health care personnel and other people when they attend for their dialysis sessions. They are a vulnerable group of patients who are at risk of severe COVID-19 disease due to their comorbidities and frailty $[2,19]$. Serological testing is key in monitoring seroprevalence in this highrisk category of patients, enabling continuing review and monitoring of current infection prevention and control (IPC) measures. A previous serosurvey from 316 healthcare workers in our centre during the period of this study demonstrated 6\% seroprevalence in healthcare workers directly involved in patient care [20]. Our results revealed a slightly lower seroprevalence compared to the contemporaneous seroprevalence in healthcare workers within the department and healthy adult blood donors within the North West of the UK (6.4\%) [21]. The lower seroprevalence is likely explained by the introduction of enhanced IPC measures and guidance resulting in reduced local transmission and outbreaks [22-24].

Due to the recent discovery of SARS-CoV-2, knowledge and understanding of the time host antibodies remain detectable and the immunological response to infection is limited. Out of the 32 rRT-PCR positive patients, one patient had undetectable antibodies 112 days after the rRT-PCR result on the first antibody test performed via the CE marked chemiluminescent immunoassay. It was not until 132 days after the positive rRT-PCR that anti-SARS-CoV-2 antibodies were detected in this patient via the Siemens' immunoassay. This may have been explained by the different assays used or that the initial test may have been a false negative. In all subsequent antibody tests for this patient there were detectable antibodies.

A second patient had detectable antibodies on the first and sixth antibody testing points, with undetectable antibodies in between these timepoints, of which the reason for this inconsistency is unclear. All antibody tests for this patient except for the initial test were analysed via the Siemens' assay. Of importance, the rRT-PCR testing in between the first and sixth antibody testing for this patient were negative, and is therefore, unlikely to have been caused by reinfection.

A third patient had undetectable antibodies from the second antibody test onwards. The duration between the positive rRT-PCR test and positive antibody test for this patient was 109 days, revealing a good initial duration of host antibody response. 
Table 3 Baseline demographics of the recruited haemodialysis patients

\begin{tabular}{|c|c|c|c|c|}
\hline Variable & $\begin{array}{l}\text { Total patients } \\
(269)\end{array}$ & $\begin{array}{l}\text { COVID-19 rRT-PCR } \\
\text { positive (32) }\end{array}$ & $\begin{array}{l}\text { COVID-19 rRT-PCR } \\
\text { negative (237) }\end{array}$ & $\begin{array}{l}p \text {-value } \\
\text { positive vs negative }\end{array}$ \\
\hline Age, years & $61(50-73)$ & $62(54-75)$ & $60(50-73)$ & 0.663 \\
\hline Gender, male & $177(65.7 \%)$ & $22(68.7 \%)$ & $150(63.3 \%)$ & 0.546 \\
\hline Ethnicity, Caucasian & $196(72.8 \%)$ & $25(78 \%)$ & $171(72.2 \%)$ & 0.476 \\
\hline BAME & $73(27.2 \%)$ & $7(22 \%)$ & $66(27.8 \%)$ & \\
\hline Smoking history & $32(11.9 \%)$ & $8(25 \%)$ & $24(10.1 \%)$ & 0.344 \\
\hline Weight, Kg & $76(64-89.5)$ & $81.5(63-95)$ & $75(65-89)$ & 0.405 \\
\hline $\mathrm{BMI}, \mathrm{Kg} / \mathrm{m}^{2}$ & $27(23-31)$ & $26.5(22.5-32)$ & $27(24-31)$ & 0.939 \\
\hline Diabetes mellitus & 97 (36.1\%) & $9(28.1 \%)$ & $88(37.1 \%)$ & 0.319 \\
\hline CVD & $60(22.3 \%)$ & $8(25 \%)$ & $52(21.9 \%)$ & 0.696 \\
\hline RASi & $93(34.6 \%)$ & 9 (28.1\%) & $84(35.4 \%)$ & 0.414 \\
\hline Frail (CFS $>/=5), n=189$ & 73/189 (38.6\%) & 18/28 (64.3\%) & $55 / 161(34.1 \%)$ & 0.003 \\
\hline Dialysis vintage, months & $26(11-64)$ & $42(14-71)$ & $25(10-61)$ & 0.658 \\
\hline Dialysis access, AVF & $167(62.1 \%)$ & $21(65.5 \%)$ & $146(61.6 \%)$ & 0.701 \\
\hline URR, \% & $72(65-78)$ & $69(66-77)$ & $73(67-78)$ & 0.162 \\
\hline Albumin, $g / L, n=262$ & $37(34-40)$ & $38(34-40)$ & $37(34-40)$ & 0.873 \\
\hline Ferritin, $\mathrm{ng} / \mathrm{mL}, n=262$ & $367(208-652)$ & 364 (239-706) & $368(208-647)$ & 0.761 \\
\hline TSats, \%, $n=262$ & $24(16-34)$ & $27(17-36)$ & $24(16-34)$ & 0.418 \\
\hline Vitamin D level, $\mathrm{nmol} / \mathrm{L}, n=211$ & $43(28-55)$ & $42(24-53)$ & $37(30-71)$ & 0.613 \\
\hline Haemoglobin, $g / L, n=214$ & $107(96-117)$ & $103(86-120)$ & $107(96-117)$ & 0.616 \\
\hline WCC, $\times 10^{9} / \mathrm{L}, n=214$ & $7(5-8)$ & $6.6(4-9)$ & $7(5-8)$ & 0.925 \\
\hline $\begin{array}{l}\text { Lymphocytes, } \times 10^{9} / \mathrm{L} \text {, } \\
n=214\end{array}$ & $1.1(0.7-1.45)$ & $0.75(0.5-1.2)$ & $1.10(0.8-1.5)$ & 0.005 \\
\hline Platelet count, $\times 10^{9} / L, n=214$ & $204(157-256)$ & 189 (117-262) & $207(158-254)$ & 0.286 \\
\hline \multicolumn{5}{|l|}{ Outcomes on follow-up } \\
\hline Follow up, months & $7.6(6.9-8.1)$ & $8.7(8.1-8.9)$ & $7.2(6.8-8)$ & $<0.001$ \\
\hline $\begin{array}{l}\text { COVID-19 associated hospital } \\
\text { admission }\end{array}$ & $28(10.4 \%)$ & $25(78.1 \%)$ & $3(1.26 \%)$ & $<0.001$ \\
\hline ICU admission & 3 & 3 & 0 & - \\
\hline Deaths & $18(6.7 \%)$ & $6(18.7 \%)$ & $12(5.9 \%)$ & 0.003 \\
\hline
\end{tabular}

Categorical variables are expressed as number (\%), and the $p$-value was derived using the Chi-square test. Continuous variables are expressed as median (interquartile range) and the Mann-Whitney $U$ test was used to calculate the $p$-value

$B A M E$ black Asian minority ethnicity, BMI body mass index, CVD cardiovascular disease, RASi renin-angiotensin system inhibitors, CFS clinical frailty score, AVF arterio-venous fistula, URR urea reduction ratio, WCC white cell count, TStats transferrin saturations, ICU intensive care unit

It is thought that the degree of natural immunity an individual develops might be associated with severity of infection, with reports of higher antibody titres to SARSCoV-2 in patients with a more severe clinical course of infection $[25,26]$. The patient that had undetectable antibodies from the second antibody test onwards was not admitted to hospital and one possible explanation may have been that they experienced a milder clinical course of infection and subsequently a lower titre and short-lived antibody response.

A total of 22 rRT-PCR positive patients were revealed to have detectable antibodies at a median of 242 days (IQR 233-250) from PCR positivity. The results are very encouraging in that $100 \%$ of these 22 patients who underwent serological testing at greater than 7 months after initial infection had anti-SARS-CoV-2 antibodies detectable. This finding indicates that ESRD patients receiving $\mathrm{HD}$ are able to form antibodies against COVID-19. Of importance, patients may still have cellular immunity even when antibody testing for serological immunity is undetectable.

The limitations of the study include the use of different assays used between the first baseline and subsequent antibody tests, and the decline in the number of COVID-19 positive patients who underwent antibody testing with time.

Additionally, antibody titres were unavailable to evaluate the change in levels over time. Furthermore, there 
may have been a possible volunteer bias for the epidemiologic part of the study with those consented having increased adherence to PHE guidance and IPC measures. Despite these limitations, this is the first study to investigate the serial COVID-19 antibody status in HD patients over a period of at least 7 months from initial infection, with the longest duration in one patient recorded up to 264 days from the initial rRT-PCR positive swab.

Serological testing is easy to obtain from HD patients when they attend dialysis without the need for additional phlebotomy. This is an extremely valuable tool for determining seroprevalence and guiding IPC to reduce local transmission rates. It can be used to identify vulnerable patients in whom anti-SARS-CoV-2 antibodies are undetectable, whether due to lost immunity or absence of previous exposure to COVID-19, and who are potentially more susceptible to infection, be it an initial, recurrence or due to viral reactivation [9].

\section{Conclusions}

Ongoing surveillance of asymptomatic patients with the use of serological testing is essential in continuing to reduce the risk of transmission and outbreaks amongst dialysis units and ensuring safety standards are maintained. We report a lower regional seroprevalence during the period of this study probably due to effective PHE and departmental IPC measures.

Our data has revealed that the vast majority of highrisk ESRD patients receiving maintenance HD develop a good humoral response, which in surviving patients is present beyond 7 months after infection with COVID19, providing hope of similar protection with vaccines now recently approved. Further larger and long-term studies are warranted to provide information on the duration of immune protection against COVID-19 infection and to determine if the same response can be achieved with vaccination.

\begin{abstract}
Abbreviations
BMI: Body mass index; CFS: Clinical frailty score; CVD: Cardiovascular disease; RASi: Renin-angiotensin system inhibitors; COVID-19: Coronavirus disease 2019; ESRD: End-stage renal disease; HD: Haemodialysis; IPC: Infection prevention and control; IQR: Interquartile range; NP: Nasopharyngeal; PD: Peritoneal dialysis; PHE: Public Health England; rRT-PCR: Real-time reverse transcription polymerase chain reaction; SARS-CoV-2: Severe acute respiratory syndrome coronavirus-2 virus; SKS: Salford Kidney Study
\end{abstract}

\section{Supplementary Information}

The online version contains supplementary material available at https://doi. org/10.1186/s12882-021-02366-2.

Additional file 1: Supplementary Table 1. Cox-regression analysis for all-cause mortality in the whole population (Multivariate model).

\section{Acknowledgements}

The analysis of the initial SARS-CoV-2 antibody testing was performed by Medical Diagnostics Ltd. in conjunction with Affinity Biomarker Labs.

\section{Authors' contributions}

Patient recruitment or data collation, or both- OW, FM, FS, YMB, CC, CS, DE, $A V B, J O, N M$, EF. Conception or design, or analysis and interpretation of data, or both- OW, RC, PK, DP. Drafting the article or revising it - OW, RC, PK, DP. Providing intellectual content of critical importance to the work describedOW, RC, IA, RO, PK, DP. Final approval of the version to be published- All authors.

\section{Funding}

This research did not receive any specific grant from funding agencies in the public, commercial, or not-for-profit sectors.

\section{Availability of data and materials}

The datasets used and analysed during the current study are available from the corresponding author on reasonable request.

\section{Declarations}

Ethics approval and consent to participate

This research work has been performed in accordance with the Declaration of Helsinki and Salford Kidney Study has ethical approval obtained from the North West - Greater Manchester South Research Ethics Committee, UK (reference number: 15/NW/0818). All 269 patients involved in our observational analysis have signed an informed consent.

\section{Consent for publication}

Not applicable.

\section{Competing interests}

The analysis of the initial SARS-CoV-2 antibody testing was performed by Medical Diagnostics Ltd. in conjunction with Affinity biomarkers Labs free of charge. None of the authors has any other conflict of interest in relation to this manuscript.

\section{Author details}

${ }^{1}$ Department of Renal Medicine, Salford Royal NHS Foundation Trust, Salford M6 8HD, UK. 2Faculty of Biology, Medicine and Health, University of Manchester, Manchester, UK. ${ }^{3}$ Research and Innovation, Salford Royal NHS Foundation Trust, Salford, UK.

Received: 24 January 2021 Accepted: 20 April 2021

Published online: 27 April 2021

References

1. Liu YC, Kuo RL, Shih SR. COVID-19: the first documented coronavirus pandemic in history. Biom J. 2020;43(4):328-33.

2. Goicoechea M, Cámara LA, Macías N, de Morales AM, Rojas ÁG, Bascuñana A, et al. COVID-19: clinical course and outcomes of 36 hemodialysis patients in Spain. Kidney Int. 2020;98(1):27-34. https://doi. org/10.1016/j.kint.2020.04.031.

3. Alberici F, Delbarba E, Manenti C, Econimo L, Valerio F, Pola A, et al. A report from the Brescia renal COVID task force on the clinical characteristics and short-term outcome of hemodialysis patients with SARS-CoV-2 infection. Kidney Int. 2020;98(1):20-6. https://doi.org/10.101 6/j.kint.2020.04.030

4. Gansevoort RT, Hilbrands LB. CKD is a key risk factor for COVID-19 mortality. Nat Rev Nephrol. 2020;16(12):705-6. https://doi.org/10.1038/ s41581-020-00349-4.

5. Guo L, Ren L, Yang S, Xiao M, Chang D, Yang F, et al. Profiling early Humoral response to diagnose novel coronavirus disease (COVID-19). Clin Infect Dis. 2020;71(15):778-85. https://doi.org/10.1093/cid/ciaa310.

6. Augustine R, Das S, Hasan A, Salam SA, Augustine P, et al. Rapid AntibodyBased COVID-19 Mass Surveillance: Relevance, Challenges, and Prospects in a Pandemic and Post-Pandemic World. J Clin Med. 2020;9(10):3372.

7. Widders A, Broom A, Broom J. SARS-CoV-2: the viral shedding vs infectivity dilemma. Infect dis health. Infect Dis Health. 2020;25(3):210-5. https://doi. org/10.1016/j.idh.2020.05.002.

8. Liu WD, Chang SY, Wang JT, et al. Prolonged virus shedding even after seroconversion in a patient with COVID-19. J Inf Secur. 2020;81(2):318-56.

9. Gousseff M, Penot P, Gallay L, Batisse D, Benech N, Bouiller K, et al. Clinical recurrences of COVID-19 symptoms after recovery: viral relapse, reinfection 
or inflammatory rebound? J.Infect. 2020;81(5):816-46. https://doi.org/10.101 6/j.jinf.2020.06.073

10. De Vriese AS, Reynders M. IgG antibody response to SARS-CoV-2 infection and viral RNA persistence in patients on maintenance hemodialysis. Am J Kidney Dis. 2020;76(3):440-1. https://doi.org/10.1053/j.ajkd.2020.05.009.

11. Padoan A, Cosma C, Sciacovelli L, Faggian D, Plebani M. Analytical performances of a chemiluminescence immunoassay for SARS-CoV-2 lgM/ IgG and antibody kinetics. Clin Chem Lab Med. 2020;58(7):1081-8. https:// doi.org/10.1515/cclm-2020-0443.

12. Public Health England. Evaluation of sensitivity and specificity of four commercially available SARS570 CoV-2 antibody immunoassays. 2020 (Available from: https://assets.publishing.service.gov.uk/government/uploa ds/system/uploads/attachment_data/file/891598/Evaluation_of_Roche_ Elecsys_anti_SARS_CoV_2_PHE_200610_v8.1_FINAL.pdf). Accessed 20 Nov 2020

13. Baron RC, Risch L, Weber M, Thiel S, Grossmann K, Wohlwend N, et al. Frequency of serological non-responders and false-negative RT-PCR results in SARS-CoV-2 testing: a population-based study. Clin Chem Lab Med. 2020; 31:58(12):2131-40.

14. Zhang Z, Bi Q, Fang S, Wei L, Wang X, He J, et al. Insight into the practical performance of RT-PCR testing for SARS-CoV-2 using serological data: a cohort study. Lancet Microbe. 2021;2(2):79-87.

15. Surkova E, Nikolayevskyy V, Drobniewski F. False-positive COVID-19 results: hidden problems and costs. Lancet Respir Med. 2020;8(12):1167-8. https:/ doi.org/10.1016/S2213-2600(20)30453-7.

16. Rockwood K, Song X, Macknight C, Bergman H, Hogan DB, McDowell I, et al. A. Global clinical measure of fitness and frailty in elderly people. CMAJ. 2005;173(5):489-95. https://doi.org/10.1503/cmaj.050051.

17. Hewitt J, Carter B, McCarthy K, Pearce L, Law J, Wilson FV, et al. Frailty predicts mortality in all emergency surgical admissions regardless of age. An observational study. Age Ageing. 2019;48(3):388-94. https://doi.org/10.1 093/ageing/afy217.

18. Chinnadurai R, Clarke NW, Kalra PA. Associations of urological malignancies with renal progression and mortality in advanced chronic kidney disease: a propensity-matched cohort study. BMC Nephrol. 2020;21(1):202. https://doi. org/10.1186/s12882-020-01859-w.

19. Ng JH, Hirsch JS, Wanchoo R, Sachdeva M, Sakhiya V, Hong S, et al. Outcomes of patients with end-stage kidney disease hospitalized with COVID-19. Kidney Int. 2020;96(6):1530-9.

20. Poulikakos D, Sinha S, Kalra PA. SARS-CoV-2 antibody screening in healthcare workers in a tertiary Centre in north West England. J Clin Virol. 2020;129:104545. https://doi.org/10.1016/j.jcv.2020.104545.

21. Sero-surveillance of COVID-19. Public Health England. Updated 2 October 2020. (Available from: https:/www.gov.uk/government/publications/nationa I-covid-19-surveillance-reports/sero-surveillance-of-covid-19). Accessed 28 Dec 2020.

22. National Institute for Health and Care Excellence (NICE) website. COVID-19 rapid guideline: dialysis service delivery. NICE guideline [NG160]. (Available from: https://www.nice.org.uk/guidance/ng160). Accessed 28 Dec 2020.

23. Public Health England COVID-19: Guidance for maintaining services within health and care settings Infection prevention and control recommendations. Public Health England. Version 1.0 published 20 August 2020; Revised Version 1.1 published 21 January 2021. https://assets. publishing.service.gov.uk/government/uploads/system/uploads/attachment_ data/file/954690/Infection_Prevention_and_Control_Guidance_January_2 021.pdf. Accessed 28 Dec 2020

24. Recommendations for Minimising the Risk of Transmission of SARS-CoV-2 (COVID-19) in UK Adult Haemodialysis Units. KQulP COVID-19 HD Ensuring Patient Safety Work Stream. Version 3, 20 June 2020. (Available from: https:// britishrenal.org/wp-content/uploads/2020/07/Recommendations-forminimising-risk-oftransmission-of-COVID-19-on-UK-ha...-002.pdf). Accessed 7 Jan 2021.

25. Long QX, Liu BZ, Deng HJ, Wu GC, Deng K, Chen YK, et al. Antibody responses to SARS-CoV-2 in patients with COVID-19. Nat Med. 2020;29:1-4.

26. Xie J, Ding C, Li J, Wang Y, Guo H, Lu Z, et al. Characteristics of patients with coronavirus disease (COVID-19) confirmed using an IgM-lgG antibody test. J Med Virol. 2020;92(10):2004-10. https://doi.org/10.1002/jmv.25930.

\section{Publisher's Note}

Springer Nature remains neutral with regard to jurisdictional claims in published maps and institutional affiliations.

Ready to submit your research? Choose BMC and benefit from:

- fast, convenient online submission

- thorough peer review by experienced researchers in your field

- rapid publication on acceptance

- support for research data, including large and complex data types

- gold Open Access which fosters wider collaboration and increased citations

- maximum visibility for your research: over $100 \mathrm{M}$ website views per year

At $\mathrm{BMC}$, research is always in progress.

Learn more biomedcentral.com/submissions 